\title{
Research on the Teaching Reform of Individualized Engineering Training Under the Credit System
}

\author{
Yuan Gong a \\ Office of Educational Administration, Wuhan University of Science and Technology, Wuhan, Hubei, \\ 430081, China \\ acircless@163.com
}

Keywords: credit system; individualization; innovation ability; engineering training; teaching reform.

\begin{abstract}
Engineering training is an indispensable link in the training of engineering professionals and plays an important role in training students' practical ability and innovation ability. With the deepening of the credit system reform in Colleges and universities, the traditional centralized engineering training mode has been unable to meet the needs of teaching in the new situation, and the reform of engineering practice teaching is imminent. In this study, update teaching ideas, to construct the credit system reform training system, establish a hierarchical and modular training mode, reform teaching means and methods and so on. We must put the essence of the credit system into engineering practice teaching, pay attention to the individual differences of students, give full play to students' initiative and motivation, strengthen students' practical ability highlight and innovation ability, and spotlight the training of the students' personality.
\end{abstract}

\section{学分制下突显个性化培养的工程实训教学改革研究}

\author{
龚园 \\ 武汉科技大学教务处, 中国湖北武汉, 430081, 中国
}

摘 要: 工程实训是工科专业人才培养必不可少的实践环节, 对培养学生实践动手能力和创新 能力起着重要作用。随着高校学分制改革的深入, 传统集中式工程实训模式已不能适应新形 势下的教学需求, 工程实训教学改革迫在眉睫。本研究从更新教学理念, 构建适应学分制改 革的实训体系, 建立层次化模块化的实训模式, 改革实训教学手段和方法等, 将学分制的精 髓融入到工程实训教学之中, 注重学生个体差异, 充分发挥学生自主性和能动性, 强化学生 实践动手能力和创新能力, 突显学生个性化培养。

关键词: 学分制; 个性化; 创新能力; 工程实训; 教学改革

\section{1. 问题提出}

学分制是以选课为核心, 教师指导为辅助, 通过绩点和学分, 衡量学生学习质和量的综合教 学管理制度 [1]。学分制优势在于尊重学生个体差异, 因材施教, 给予学生自由的学习空间, 让学生能够根据自身学习情况制订学习计划、选择学习内容、安排学习时间, 更好地激发了 学生自主性和能动性, 促进学生个性化发展。十九大报告指出：“优先发展教育事业, ......, 实现高等教育内涵式发展”, 中办国办印发《关于深化教育体制机制改革的意见》明确指出:

“健全促进高等教育内涵发展的体制机制。完善学分制, 实施灵活的学习制度”, 都为高等 教育积极推进学分制改革提出了明确要求。

随着高校学分制管理推进, 学分绩点的衡量标准、课程排选改革都有着行之有效的方法, 改 革深入的难点在于实践课程的改革, 作为工科专业必要环节工程实训, 同样面临着亟待解决 的问题: (1)学分制教学模式与集中实训的矛盾, 学分制下传统班级概念被打破, 学生自由选 课、上课, 以班为单位的集中实训不再可能; (2)集中实训转为分散实训, 且以学生个体为单 
位, 学生学习时间、学习内容不统一, 传统的实训教学体系设置不能满足教学需要; (3)学生 在白天黄金时间进行专业课程学习, 可能下午或晚上、周末才能工程实训, 与传统的工程实 训管理模式相冲突; (4)随着数控加工、柔性制造系统等一批先进制造设备与技术的引入, 工 程训练实践由传统的车钳铣刨磨铸锻焊等加工工艺, 拓展到先进制造及电工电子技术, 实训 内容不断丰富, 相对实训学时却没有增加, 有些还反而减少, 造成实训教学内容与学时相对 不足的矛盾, 因此, 在学分制下, 如何推进工程实训教学改革, 更好地促进学生个性化培养, 是我们研究的重点。

\section{2. 转变思想观念, 树立个性化实训教学理念}

改革与发展的前提是更新思想观念, 只有思想认识达成共识, 才能将改革深入到底。工程实 训是工程教育重要部分, 应遵循 CDI0 (Conceive 构思、Design 设计、Implement 实践、Operate 运作）工程教育规律, 着重强调将构思、设计、实践、运作等关键环节融入实训过程, 提升 学生工程实践能力。然而, 在学分制下, 工程实训管理者、教师更要在思想上树立个性化的 育人理念, 更加注重学生个体差异, 实施因材施教, 进行个性化培养与训练, 将个性化与工 程创新能力培养紧密结合在一起, 发挥学生自主性和主观能动性, 激发学生创新灵感, 切实 提升学生工程实践能力和创新能力。

我校实施 “凸显个性” 为目标 “开放+自主” [2] 的学分制管理模式, 在工程实训环节, 将个 性化 (Individualization) 的培养融入实践教学全过程, 发挥学生自主性和能动性, 培养学 生解决实际工程问题的能力, 形成具有我校特色的个性化工程实践育人理念 I-CDI0, 并贯穿 到实训教学、学科竞赛、创新创业等各个环节, 教学管理人员到指导教师, 至上而下达成统 一共识, 以思想引领指导教学实践, 为个性化实践育人提供有效保障。

\section{3. 做好顶层设计, 构建工程实训教学体系}

加强工程实训内涵建设, 不断拓展工程实训内容, 以提升大学生工程实践能力和创新能力为 导向, 做好顶层设计, 针对不同专业年级学生, 通过工程训练、科学竟赛、自主设计和自主 创新等实践途径, 构建具有学校特色的工程实训教学体系。

我校以工程训练、科学竟赛、创新创业项目为基础, 构建并实施 “ $1+1+\mathrm{N}$ ” 的突显个性化的工 程实训体系, 即针对不同专业, 在 1-2 年级, 针对机械类、近机械类、非机械类专业不同层 次要求, 实施基础的工程训练实训教学, 在车钳铣刨磨铸锻焊等基础加工, 数控机床、加工 中心等高端加工, 以及电工电子、3D 打印、激光雕刻等先进制造环节, 培养学生基本实践动 手能力; 其次, 鼓励 1-3 年级学生参与工程训练综合能力竞赛、机械创新大赛、机器人大赛 等竞赛项目, 通过实践应用激发学生兴趣爱好, 实现赛练结合的目的, 进一步提升学生实践 动手和创新能力; 最后, 面向 3-4 年级学生, 倡导学生多动脑、勤动手, 将自己所思所想变 成现实, 鼓励学生自主创新设计、加工制造零件、产品, 切实强化学生工程创新能力。

\section{4. 注重学生个性化培养, 实施学分制下工程实训教学模式改革}

发展学生的个性, 其实质就是尊重学生与生俱来的潜能, 尊重学生的个人兴趣爱好及自主发 展的愿望, 因个体差异和兴趣去向的不同需要分层次实施培养 [3], 这也是学分制管理的必然 要求。因此, 工程实训改革的核心在于围绕学分制管理特点, 将连续的实训内容设置成独立 模块或项目, 建立工程实训选课制, 突显学分制下个性化思想, 实现学分制下工程实训教学 模式改革。

为对接学分制改革, 我校在 2012 年就根据不同专业, 改革了工程实训培养方案, 将工程训练 实践教学划分为 “三层次” , 即工程认知与基础实训、学科基础技能实训和多学科知识融合 实践、综合创新实践训练; 与之对应形成 “三能力” , 即基本实践能力、专业实践能力, 以及 实践创新能力; 根据 “三层次、三能力” 的划分, 我们将工程实训车、钳、铣刨磨、铸锻焊、 
数控加工、电工电子、3D 打印等每个工种划分 2-4 个相对独立又递进的操作模块, 即 “多模 块”。随着多年探索、实践和完善, 形成了 “模块+层次” [4]教学模式改革, 确立了 “三层 次、三能力、多模块” 的工程训练实践教学个性化培养模式。该模式下学生根据所在专业人 才培养要求, 完成相应模块的操作训练, 就能获得相应的学分和能力等级, 有兴趣的学生, 还可以继续选择下一层次的训练模块, 就像游戏通关一样; 学生可以自由的选择实训模块及 实训时间, 学什么, 什么时候学都由自己说了算, 极大激发了学生自主学习热情, 满足学分 制下个性化培养需求的同时，提升了学生实践动手能力和创新能力。

\section{5. 加强工程实训课程内涵建设, 改进教学手段和方法}

以中国制造 2025、工业 4.0 为远景和目标, 结合工程实训基本要求, 充实和优化工程实训教 学内容, 夯实机械加工基础, 引进高端制造设备增设训练内容, 提升学生实践动手能力和创 新能力。如车钳铣刨磨学生必须完成基础加工和训练, 增加数控加工、电工电子、3D 打印、 激光雕刻等实训项目, 由学生自行设计并加工出实物。同时, 针对学分制下实训学时不足的 现状, 利用现代化信息技术, 加强工程实训网络在线课程建设, 将实训内容按知识点、操作 过程等进行划分, 录制教学视频, 建成满足实训教学需求的 MOOC 课程。

更新实训教学手段和方法, 充分利用在线课程, 实现 “线上+线下、课上+课下” 相互结合的 实训模式, 学生课下通过视频提前预习, 带着问题到训练中心, 由指导老师有针对性地指导, 通过课上实践操作, 检验所掌握的知识和操作技能, 形成工程实训中 “翻转训练” 的教学方 式, 将学习的决定权从教师转移给学生, 在实训中由学生提问, 教师有针对性指导和解答, 更好地调动学生积极性和主动性, 促进学生个性化培养。

\section{6. 搭建开放创新训练综合平台, 促进学生实践创新能力培养}

学生的个性化培养与实践创新能力的提升息息相关, 创新往往就是单独个体天马行空的灵机 一动。因此, 我们要充分利用工程训练中心现有仪器设备、场所和师资优势, 搭建开放创新 训练综合平台，争取政策支持、整合资源优势，推进全校创新实践教育，营造良好氛围。

落实组织保障, 联合教务处、学工处、团委、工程训练中心和相关学院, 为平台建立提供政 策、条件、师资等有力支持; 设置创新学分, 并纳入毕业总学分, 对每位学生提出创新实践 的硬性要求; 实施项目抓手, 以大学生创新创业项目、学科竞赛项目、导师课题项目、创业 项目等为载体，引导学生跟着项目走、跟着项目做; 鼓励创意竞争，评价有计划、有想法、 有成效的创意团队，竞争入驻平台创意空间，为学生提供良好的创新创业条件; 建立导师队 伍, 鼓励教师积极参与指导学生实践, 在设备基本操作使用、设计灵感、创新创业方案、学 科竞赛等方面为学生提供强有力的智力和技术支持。通过开放创新训练综合平台, 给予学生 自由的空间, 引导学生个性化发展, 让学生随时可以将自己所思、所想、所创变为现实, 无 论是成功还是失败, 都在思考、设计、执行、运作的实践过程中提升了创新能力, 鼓励更多 怀揣梦想的学生能大胆尝试、小心求证, 勇敢迈出第一步。

\section{References}

[1]. Baike. Credit system [DB/OL]. https:// baike. baidu.com/item / \% E5 \% AD \% A6\% E5\% 88\% 86\% E5\% 88\%B6/87418? fr =Aladdin,2017-07-28/2018-2-27.

[2]. Cheng Guangwen, Gong Yuan. Research on the reform of personnel training mode for local colleges facing the industry[J]. Chinese University Teaching,2015(11):33.

[3]. Fu Liling, Yang Ping etc. Exploring the New Mode of Engineering Training to Implemente Personalized Hierarchical Cultivation[J]. Laboratory research and exploration,2013,32(1):86. 
[4]. Gong Yuan, Mei Dan, Research on the reform of metalworking practice teaching system in engineering colleges[J]. Chinese Power Education,2013(2):130. 